\title{
Motivation, Satisfaction, and Innate Psychological Needs
}

\author{
Michelle M. Mason \\ Troy University, Montgomery, AL, USA
}

michellemason@troy.edu; michelle.mason.phd@gmail.com

\begin{abstract}
This study investigates the roles that innate psychological needs and student satisfaction have on doctoral student motivation. A total of 125 doctoral students completed surveys that included how autonomous, competent, satisfied with their program, and motivated they felt. Information about their sense of relatedness to their advisor was also collected. Autonomy was defined as the freedom to do one's own research. Competence was the overall level of competence the students felt they had in graduate school. A sense of relatedness toward the students' advisor was the relatedness factor. Hierarchical regression analyses were completed to investigate the relationships among autonomy, competence, relatedness, satisfaction, and motivation to continue graduate school. The results indicated that there was a positive relationship between motivation to continue and autonomy, competence, and relatedness. Autonomy and relatedness were positively related to satisfaction, but competence was not. The relationship between autonomy and relatedness was mediated by satisfaction. The importance of students' having autonomy over their research indicates that advisors should give their students independence in developing their research agendas. Having a collegial relationship with advisors is also critical for students' satisfaction and motivation, so these relationships should be encouraged. Limitations, implications, and further research are discussed.
\end{abstract}

Keywords: doctoral students, motivation, satisfaction, autonomy, competence, relatedness

\section{Introduction}

The high attrition rate of doctoral students has been described as a "hidden crisis" (Lovitts \& Nelson, 2000). Research has indicated that 30 percent to 50 percent of doctoral students did not complete their degrees (Berelson, 1960, p. 168; Bowen \& Rudinstine, 1992, chap. 6; Kehrhan, Sheckley, \& Travers, 1999; Lovitts, 1996; Most, 2008; Nerad \& Miller, 1996). More specifically, Nerad and Miller (1996) reported that different disciplines have different completion rates: 27\% of biological and physical science students, $34 \%$ of engineering students, $47 \%$ of social science students, $52 \%$ of professional program students, and $56 \%$ of humanities students did not finish

Material published as part of this publication, either on-line or in print, is copyrighted by the Informing Science Institute. Permission to make digital or paper copy of part or all of these works for personal or classroom use is granted without fee provided that the copies are not made or distributed for profit or commercial advantage AND that copies 1) bear this notice in full and 2) give the full citation on the first page. It is permissible to abstract these works so long as credit is given. To copy in all other cases or to republish or to post on a server or to redistribute to lists requires specific permission and payment of a fee. Contact Publisher@InformingScience.org to request redistribution permission. their doctoral degrees. In contrast, over $90 \%$ of students who attend professional schools of law, business, and medicine complete their programs (Bowen \& Rudenstine, 1992). When students leave graduate study, it impacts departments and faculty, universities, society, and the students who leave. Departments and faculty are impacted because low graduating departments may be discontinued. Universities have to pay for recruiting 
new students to replace the students who leave. When doctoral students leave doctoral study, our society has fewer educated people who could work in a variety of fields. Individuals who leave doctoral programs suffer financial, professional, and personal setbacks (Lovitts, 2001, chap. 1). While completers and noncompleters often have financial aid debt, the noncompleters are less likely to find well-paying jobs (Lovitts, 2001, chap. 1). Noncompleters also feel demoralized when they leave their doctoral programs (Lovitts, 2001, chap. 1). For instance, students who drop out of graduate schools have long-term emotional consequences including regret, disappointment, and frustration (Willis \& Carmichael, 2011).

Academic ability has not been a predictor of academic failure in graduate schools (Berelson, 1960; Lovitts, 2001, chap 6; Tucker, 1964). For instance, sixty percent of graduate students who had less than a 3.00 grade point average completed their doctoral education, which was comparable to the overall sample (Tucker, 1964). More recently, Lovitts (2001, chap 6) reported that noncompleters did not have significantly different grade point averages from completers. However, graduate school deans, faculty, and the students themselves attribute attrition to the students, and graduate schools have sought to ameliorate this problem by emphasizing selection criteria, even though this strategy has not been proven successful (Lovitts, 1996; 2001, chap. 1).

\section{Innate Psychological Needs}

One theory that may help explain the high attrition rate of graduate students is Self-Determination Theory (SDT). SDT describes the socio-context variables that assist and impede human motivation, performance, and development (Deci, Vallerand, Pelletier, \& Ryan, 1991; Deci \& Vansteenkiste, 2004). These socio-context variables are innate psychological needs: autonomy, competence, and relatedness (Deci \& Ryan, 1994; Deci et al., 1991; Ryan \& Deci, 2000). When people have autonomy, their behavior is self-determined, and they have the option of choosing what they do. In other words, they are not controlled (Black \& Deci, 2000). Competence is understanding how to achieve desired outcomes and having the self-efficacy to carry out the actions required in the specific context (Deci et al, 1991). A feeling of relatedness is the feeling of being valued and cared for. A sense of relatedness provides a dual role: $(a)$ it provides support for intrinsic motivation and $(b)$ it gives people incentives to do activities that are valued by significant others (Deci \& Ryan, 2000; Deci et al., 1991; Ryan \& Deci, 2000). Research indicates that positive outcomes (such as interest, enjoyment, lower anxiety, fewer grade-focused goals, higher self-regulation, higher course performance, and persistence) occur when these innate psychological needs are met (Black \& Deci, 2000; Vansteenkiste, Simons, Lens, Sheldon, \& Deci, 2004).

\section{Autonomy}

In one research study, undergraduate participants were either told that they must do the task or they might do the task, with the former being controlling and the latter being autonomysupportive. When the participants were in the group with both intrinsic motivation framing and autonomy-support, these participants had higher test performance and free-choice persistence than the participants in all other conditions, including the intrinsic goal framing only condition (Vansteenkiste et al., 2004). Participants who entered an undergraduate chemistry course with autonomous reasons had higher perceived competence, interest and enjoyment, lower anxiety, and fewer grade focused goals than those participants that did not enter the class autonomously. The results in the same study indicated that students who perceived their instructors as having higher autonomy support had higher self-regulation, higher perceived competence, more enjoyment, and lower anxiety than those who did not perceive their instructors as autonomy-supportive (Black \& Deci, 2000).

Research demonstrates that graduate students' autonomy is related to graduate student program satisfaction with graduate programs and completion of degree (Feild, Holley, \& Armenakis, 
1974; Ferrer de Valero, 2001; Kluever, 1997; Madden \& Carli, 1981; Wasburn-Moses, 2008). Graduate students who felt they were able to choose their own coursework were more satisfied (intrinsically and extrinsically) (Feild et al., 1974). Social psychology graduate students, who perceived high personal control and independent thought and action, were more satisfied with graduate school than those with lower levels of perceived control and independence. Satisfaction, in this case, was measured by ratings of how satisfied they were compared to other students, with their own performance in graduate school, and their relationships with faculty and other students (Madden \& Carli, 1981). Gregg (1971) reported that faculty-student collegiality was positively related to graduate student program satisfaction (as defined as satisfaction with climate, faculty, and expectations, among others). Collegiality included being treated as a junior colleague, faculty seeking students' ideas, graduate student input, and department decision-making, and not doing "grunt" work. Being treated as a junior colleague (being able to engage in one's own research interests) has also been reported as being related to doctoral student progress and completion of degree (Ferrer de Valero, 2001; Girves \& Wemmerus, 1988). Students enrolled in high completion departments were able to choose courses based on their interests (Ferrero de Valero, 2001). Similarly, education doctoral students who graduated felt that they had greater independence and personal responsibility than those who did not (Kluever, 1997).

\section{Competence}

Autonomy and competence have been demonstrated as having positive relationships to satisfying learning experiences (Jang, Reeve, Ryan, \& Kim, 2009). Autonomy and competence was found to be positively related to high engagement, high intrinsic motivation, low proneness to negative affect, and achievement in South Korean high school students (Jang, et al, 2009). Competence also has been demonstrated to be related to satisfaction with graduate programs (Field et al., 1974; Madden \& Carli, 1981).

Uqdah, Tyler, and DeLoach (2009) investigated the relationships of global, academic, interpersonal, and leisure competence and reported that leisure competence was negatively related to depression scores in African American psychology graduate students. Other studies indicate that self-efficacy, a construct similar to competence, influences graduate school productivity and progress. Self-efficacy is the belief that one is proficient at organizing and implementing actions to produce desired outcomes (Bandura, 1997). While there has not been research investigating the role of self-efficacy on graduate student motivation and graduate school program satisfaction, there has been research on self-efficacy for doing research (Brown, Lent, Ryan, \& McPartland, 1996; Hollingsworth \& Fassinger, 2002; Love, Bahner, Jones, \& Nilsson, 2007; Paglis, Green \& Bauer, 2006). Specifically, research self-efficacy has a unique and positive effect on research productivity beyond the effect of research training environment in graduate students (Brown et al, 1996; Hollingsworth, \& Fassinger, 2002). Moreover, graduate students who had high research self-efficacy had made more progress on their dissertation than those who did not report high research self-efficacy (Faghihi, Rakow, \& Ethington, 1999).

\section{Relatedness}

Studies have shown that each of the senses of relatedness to parents, peers, and teachers has an individual effect on motivation and engagement (Furrer \& Skinner, 2003; Wentzel, 1998). Furrer and Skinner (2003) investigated how feelings of relatedness impact academic performance and engagement in third- through sixth-graders. They observed that a sense of relatedness to parents increased behavioral engagement and a feeling of relatedness to teachers increased emotional engagement. Peers had the least effect on engagement, especially when children had high relatedness to parents and teachers. 
A feeling of relatedness with an advisor has been reported as having positive outcomes for graduate students (Faghihi et al, 1999; Lan \& Williams; 2005; Maton, Wimms, Grant, Wittig, Rogers, \& Vazquez, 2011; Paglis et al, 2006; Tenenbaum, Crosby, \& Gliner, 2011; Zhao, Golde, \& McCormick, 2007). Zhao and colleagues (2007) reported that when an advisor has a "personal touch" (i.e., shows interest in the student's personal life, provides emotional support, and demonstrates caring for the whole person) graduate students have higher satisfaction with those relationships than those with advisors without those attributes. Positive advisor relationships have been indicated to positively affect personal and self-fulfillment for students in the science, mathematics, engineering, and social science disciplines (Nettles \& Millett, 2006, chap. 11). Psychosocial mentoring (i.e., respecting the student as an individual) has been reported as having a positive relationship with graduate student program satisfaction with their studies and the overall graduate experience (Maton et al, 2011; Tenenbaum et al., 2001).

Beyond graduate student program satisfaction, relatedness with advisors has been indicated to have a positive impact on productivity (Paglis et al, 2006), dissertation progress (Faghihi et al, 1999), time to degree (Wao \& Onwuegbuzie, 2011), and high levels of completion within a department (Ferrer de Valero, 2001). When students received mentoring from their advisors, they submitted more conference papers, journal articles, book chapters, and grant proposals since the beginning of their doctoral studies than those who did not receive such mentoring (Paglis et al, 2006). Students who worked with advisors who had high standards and were supportive were more motivated and productive than the students who did not have advisors with these qualities (Lan \& Williams, 2005). When advisors met monthly with students and provided support, students graduated more quickly than when advisors did not spend time with their students (Wao \& Onwuegbuzie, 2011). Individuals who were more satisfied with their relationship with their advisor graduated in a shorter amount of time than those who were not satisfied (Potvin \& Tai, 2011).

Advisors play a critical role in doctoral students' decision to complete their doctoral program (Lovitts, 2001, 2008). In fact, Bair and Haworth (1999) reported in their metasynthesis that the most recurrent finding for graduate student completion was the relationship between the advisor and completion of doctoral programs. Moreover, students indicate that one of the reasons students leave graduate school is because of bad advising (Gardner, 2008). In regard to relatedness, completers felt their advisors were more interested in them than noncompleters felt (Lovitts, 2001, chap. 7). Furthermore, completers felt more satisfied with their relationship with their advisors than did noncompleters. Similarly, Ferrer de Valero (2001) reported that students in high completion departments reported that the student-advisor relationship was nurturing, and most students in that group reported that they saw their advisor as a friend.

All three of these innate psychological needs (autonomy, competence, and relatedness) must be met to improve these positive outcomes; if only one or two are met, then the outcomes are not as positive (Deci et al, 1991). When Martens and Kirchner (2004) investigated the relationship between autonomy, competence, relatedness, and intrinsic motivation, they reported that autonomy, competence, and relatedness predicted intrinsic motivation. More importantly, their results indicated that the three innate psychological needs were so strongly correlated that they appeared to be a single factor. That is, if the social-context allows for one of the innate psychological needs to be met, then the other innate psychological needs are supported as well.

\section{Motivation and Graduate Student Program Satisfaction}

Research has indicated that satisfaction with one's programs, especially the doctoral students' realization of their expectations, is critical for doctoral completion (Bair \& Haworth, 1999). Specifically, satisfaction has been measured by quality of graduate program, communication between students and administration and faculty, consistency of evaluation across faculty, treating students as professionals, and adequate guidance (Bair \& Hayworth, 1999). It has been reported that grad- 
uate students who had low levels of graduate student program satisfaction were more likely to have seriously considered leaving graduate school than those who had high levels of satisfaction (Hesli, Fink, \& Duffy, 2003). Doctoral students who were less satisfied with their intellectual development and program of study were less likely to complete their programs (Lovitts, 2001, chap. $6)$.

\section{Motivation and Completion}

Previous research also has indicated that motivation is a critical component of completing a doctoral program (Gardner, 2008; Ivankova \& Stick, 2006; Lovitts, 2008). Both students and faculty indicated that student motivation was a crucial factor in completion of doctoral degrees (Ferrer de Valero, 2001). Faculty members consider a lack of motivation or initiative as a critical reason for non-completion of graduate programs (Gardner, 2008). While students considered a lack of motivation to continue as one of the reasons to leave graduate school, they explained it differently than the faculty members did; they thought that the students who were not motivated did not have a good fit with graduate school (Gardner, 2008). Similarly, self-motivation (motivating oneself) was also considered critical by the faculty to completion of a doctorate (Lovitts, 2008). Motivation to continue has also been indicated to be related to graduate school completion (Bair \& Haworth, 1999). Motivation and persistence have also been studied in professional and high school students. Law students who had higher levels of program satisfaction had higher levels of study motivation and were less likely to dropout (Suhre, Jansen, \& Harskamp, 2007). In terms of persistence, the relationships of autonomy and competence to high school students' dropout have been reported to be negative. That is, when students have high levels of autonomy and competence, they have higher levels of motivation to stay in school, which predicts their high school graduation (Vallerand, Fortier, \& Guay, 1997).

Although having the innate psychological needs (autonomy, competence, and relatedness) met is reported to have positive effects on many outcomes on different populations, this study is unique in that it investigates how these innate psychological needs impact doctoral student school program satisfaction and motivation to continue. Student satisfaction is important because it has been indicated to influence completion of doctoral programs (Hesli et al, 2003; Suhre et al, 2007).

Specifically, this study investigates doctoral students' autonomy in research, overall feelings of competence in graduate school, and the sense of relatedness that graduate students have with their assigned advisor. Also, this study looks at the relatedness graduate students have with their assigned advisor, not a chosen mentor.

Given the information above, three hypotheses have been developed.

1. Autonomy, competence, and relatedness are expected to be positively related to the motivation to continue.

2. Autonomy, competence, and relatedness are expected to be positively related to the graduate student program satisfaction.

3. Graduate student program satisfaction will mediate the relationship between autonomy, competence, and relatedness, and motivation to continue. These relationships can be seen in Figure 1. 


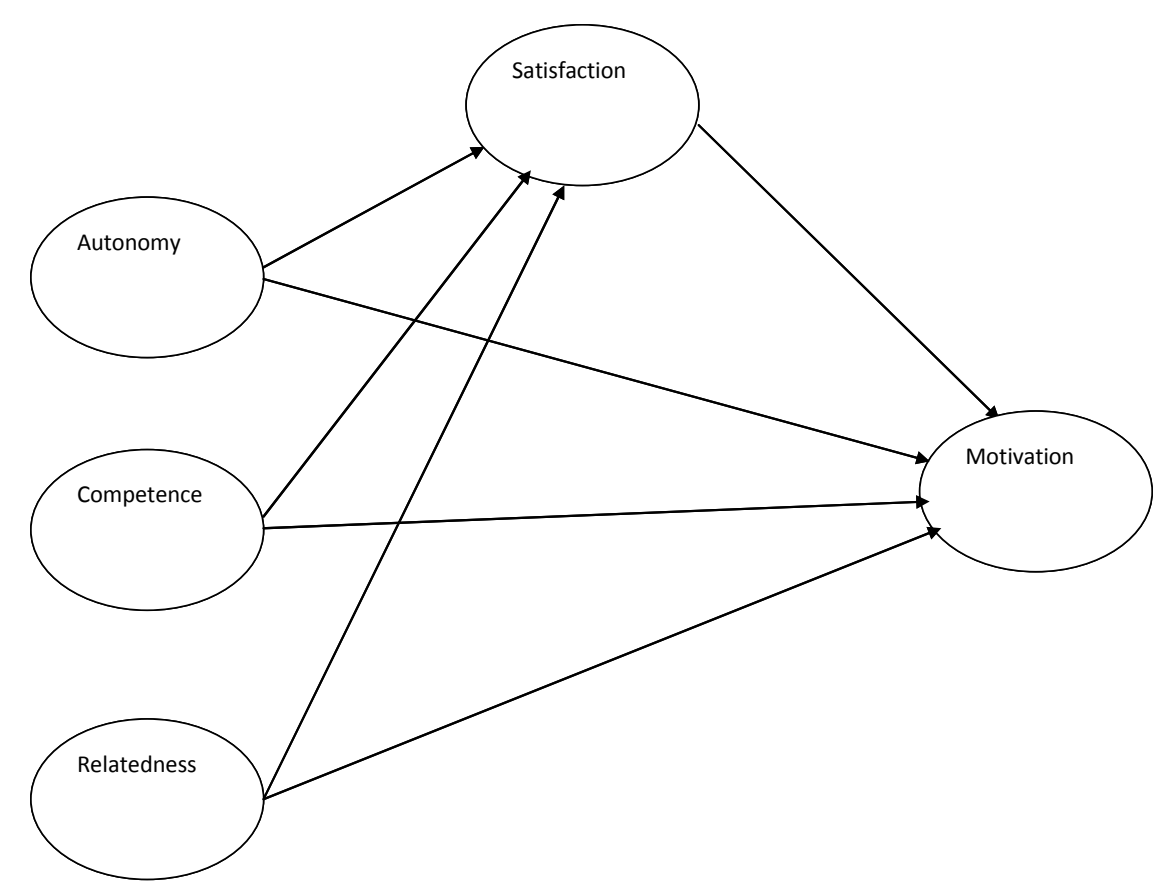

Figure 1. Proposed Model: The relationship among autonomy, competence, relatedness, graduate student program satisfaction, and motivation to continue

\section{Method}

\section{Participants and Procedure}

While all students attending the university were contacted (including master's students), only doctoral students were included in this analysis. A total of 125 doctoral students agreed to take part in the study. A cover letter with a link to the survey was sent out by e-mail to all students that attended the university. Female participants were somewhat over-represented in the sample (female $=65.2 \%$ ). Students who completed the survey were from seven different graduate schools in one university: Information Technology (1.7\%), Arts and Science (26.7\%), Business (10.8\%), Education (21.7\%), Organizational and Behavioral Sciences (32.5\%), Botany (1.7\%), and Religion $(5 \%)$. Doctoral students were enrolled in their graduate programs from less than a year to six years; see Table 1 for the categorization of years of enrollment.

Table 1. Years Graduate Students Were Enrolled in Program

\begin{tabular}{cc}
\hline Years & $\underline{\text { Percent }}$ \\
\hline Less than 1 & 1.7 \\
1 & 26.7 \\
2 & 10.8 \\
3 & 21.7 \\
4 & 32.5 \\
5 & 1.7 \\
6 & 5 \\
\hline
\end{tabular}

This study utilizes an existing data set that was collected in spring 2009. This data set was collected at a private graduate research university, and it included data about a wide-variety of grad- 
uate student experiences. The university is designated as a comprehensive doctoral/no medical or veterinary institution by the Carnegie Foundation for the Advancement of Teaching. This designation is defined as "These institutions awarded research doctorate degrees in the humanities, social sciences, and STEM* fields. They also offer professional education in fields such as business, education, engineering, law, public policy, social work, or health professions other than medicine, dentistry, or veterinary medicine" (Carnegie Foundation for the Advancement of Teaching, n.d.). The participants were able to complete the survey at their leisure. A thank-you and a reminder e-mail were sent with the survey link a week after the first contact. Once the surveys were completed, participants were then sent an e-mail describing the goals of the study. The Institutional Review Board at the institution where the data was collected gave their approval of this study.

\section{Measures}

The measures for this data set were selected after observing the patterns and trends within the data. These patterns and trends indicated that feelings of relatedness to advisor, school graduate student program satisfaction, autonomy, and competence could be measured by the constructs listed below. While it would have been beneficial to have more items for analysis, the data indicated that the items utilized in the analysis were the best indicators of the constructs being studied. All survey questions are included in Table 2.

\section{Table2. Survey Questions}

\section{$\underline{\text { Satisfaction }}$}

If I had to do it over again, I would definitely choose this graduate school. I am content that I decided to attend this graduate program.

My program has met my expectations.

\section{$\underline{\text { Relatedness }}$}

I feel a sense of connectedness to my advisor

My advisor is a "good fit" for me personally.

I consider my advisor to be my buddy.

I consider my advisor to be emotionally supportive.

\section{Motivation}

I do not feel motivated to continue this program.

\section{Competence}

I feel that I am capable of completing a graduate degree.

I feel I am a successful graduate student.

\section{Autonomy}

I believe I am free to pursue my own research interests.

Relatedness to Advisor was measured using four items; for example: "I feel a sense of connectedness to my advisor." Responses to these items were based on a Lickert five-point scale anchored by 1 (does not correspond at all) to 5 (very strongly corresponds). Cronbach's coefficient alpha 
Motivation, Satisfaction, and Innate Psychological Needs

was calculated and indicated that advisor relatedness was demonstrated to have an acceptable level of reliability $(\alpha=.89)$.

Satisfaction with graduate school was measured with three items. It was composed of a five-point scale anchored by 1 (does not correspond at all) to 5 (very strongly corresponds). For example, "If I had to do it over again, I would definitely choose this graduate school." Cronbach's coefficient alpha indicated that Satisfaction was demonstrated to have an acceptable level of reliability $(\alpha=.89)$.

Perceived competence was measured by two items. This variable assessed the overall feelings of competence in graduate school. This scale was composed of a five-point scale anchored by 1 (does not correspond at all) to 5 (very strongly corresponds). For example, "I feel that I am capable of completing a graduate degree," and "I feel I am a successful graduate student." Cronbach's coefficient alpha was calculated to investigate whether the competence was high in scale reliability. Competence was demonstrated to have an adequate level of reliability $(\alpha=.77)$.

Autonomy (Pursue own research) was measured by one item: "I believe I am free to pursue my own research interests." It was composed of a five-point scale anchored by 1 (strongly disagree) to 5 (strongly agree).

Motivation to Continue Graduate School was measured by one item, "I do not feel motivated to continue this program." It was composed of a five-point scale anchored by 1 (strongly disagree) to 5 (strongly agree). This item was reversed.

\section{Results}

\section{Preliminary Analyses}

Prior to analysis, all variables were examined for accuracy of data entry and the assumptions of multivariate analysis. Two variables were not normally distributed. Competence underwent a reflected inverse transformation that was re-reflected because it had negative skew. Motivation underwent a reflected log transformation that was re-reflected. That is, for the data to have a normal distribution the data was reflected and transformed. All variables were then converted to standard scores excluding gender.

\section{Factor analyses}

An analysis was completed to find the clearest interpretation for the graduate student program satisfaction data. A principal components analysis was implemented to determine if the dimension could be captured in fewer than three measures. The Kaiser-Meyer-Olin measure verified the sampling accuracy in the analysis, $\mathrm{KMO}=.74$. Bartlett's test of sphericity $\chi^{2}(3)=201.13, p<$ .001 . Both eigenvalues and a scree plot were utilized to assess the number of factors. The eigenvalues demonstrated a one-factor solution with the proportion of variance explained by the set of factors being $82.43 \%$. The results can be seen in Table 3 .

Table 3. Factor Loadings and Communalities for Three Variables of Satisfaction

\begin{tabular}{lcc}
\hline Variables & $\mathrm{F}_{1}$ & \multicolumn{2}{c}{$\mathrm{h}^{2}$} \\
\hline Choose School & 0.92 & 0.85 \\
Content to Attend & 0.92 & 0.84 \\
Met Expectations & 0.88 & 0.78 \\
\hline
\end{tabular}


Similarly, a factor analysis was completed to capture the dimensions of advisor relatedness. Advisor relatedness was tested with principal components analysis (PCA) to see if the construct could be captured in less than four measures. The Kaiser-Meyer-Olin measure verified the sampling accuracy in the analysis, $\mathrm{KMO}=.83$. Bartlett's test of sphericity $\chi^{2}(6)=304.89, p<.001$. Both eigenvalues and a scree plot were utilized to assess the number of factors. The eigenvalues demonstrated a one-factor solution with the proportion of variance explained by the set of factors being $78.01 \%$. The results can be seen in Table 4 .

Table 4. Factor Loadings and Communalities for Four Variables of Advisor Relatedness

\begin{tabular}{lcc}
\hline Variables & $\mathrm{F}_{1}$ & $\mathrm{~h}^{2}$ \\
\hline $\begin{array}{l}\text { Connectedness } \\
\text { Good Fit Person- }\end{array}$ & 0.92 & 0.84 \\
ally & 0.91 & 0.83 \\
Emotional Support & 0.86 & 0.74 \\
Buddy & 0.84 & 0.71 \\
\hline
\end{tabular}

The competence variables were also tested with PCA. The Kaiser-Meyer-Olin measure verified the sampling accuracy in the analysis, $\mathrm{KMO}=.50$. Bartlett's test of sphericity $\chi^{2}(1)=62.94, p<$ .001 with $81.89 \%$ of the variance explained. Both eigenvalues and a scree plot were utilized to assess the number of factors. The eigenvalues demonstrated a one-factor solution. These results can be seen in Table 5 .

Table 5. Factor Loadings and Communalities for Two Variables of Competence

\begin{tabular}{lll}
\hline Variables & $\mathrm{F}_{1}$ & $\mathrm{~h}^{2}$ \\
\hline Successful & 0.91 & 0.82 \\
Capable & 0.91 & 0.82 \\
\hline
\end{tabular}

\section{Primary analyses}

Correlations among the variables were calculated. These correlations, the means, and the standard deviations can be seen in Table 6 . All relationships among the variables were positively and significantly related. The strongest relationship was between motivation to continue and graduate student program satisfaction. The relationship between autonomy and graduate student program satisfaction was also strong.

Table 6. Intercorrelations of Doctoral Student Variables

\begin{tabular}{|c|c|c|c|c|c|c|c|}
\hline Measures & Mean & Standard Deviation & 1 & 2 & 3 & 4 & 5 \\
\hline 1. Motivation $(\log )$ & 0.76 & 0.02 & 1 & & & & \\
\hline 2. Satisfaction & 3.47 & 1.08 & $.48 * * *$ & 1 & & & \\
\hline 3. Autonomy & 3.94 & 0.98 & $.44 * * *$ & $.39 * * *$ & 1 & & \\
\hline 4. Competence (inv) & 0.77 & 0.14 & $.44 * * *$ & $0.30 * *$ & $0.31 * *$ & 1 & \\
\hline $\begin{array}{l}\text { 5. Advisor Related- } \\
\text { ness }\end{array}$ & 3.08 & 1.11 & $.32 * *$ & $.37 * * *$ & $0.26^{* *}$ & $.30 * *$ & 1 \\
\hline
\end{tabular}


To investigate the relationships of the variables, multiple analyses were completed to investigate how autonomy, competence, and relatedness were related to graduate student program satisfaction and motivation to continue. In these analyses, the regression models were utilized to assess the strength of the relationships of the variables. In this study, hierarchical regression analyses were completed to control for background variables (gender, units, and years in program) and to assess the individual strength of each of the independent variables (autonomy, competence, and relatedness). To test for mediation, the guidelines developed by Baron and Kenny (1986) were implemented. A hierarchical regression analysis with the covariates gender, units, and years in program in the first block (to control for these variables); and autonomy, competence, and relatedness in the second block was implemented to investigate their relationships with motivation. The results of the analysis indicated that Hypothesis 1, autonomy, competence, and relatedness were positively and significantly related to motivation to continue while controlling for gender, units, and years in program. $F(6,85)=7.55, p<.001 . \Delta R^{2}=.34$. These results can be seen in Table 7. These results indicate that the higher levels of autonomy, competence, and relatedness the higher the levels of motivation for completing graduate school.

\section{Table 7. Hierarchical Regression for Doctoral Student Variables on Motivation}

\begin{tabular}{llrrr}
\hline Variables & b & SE b & \\
\hline Step 1 & & & & \\
& Constant & -0.07 & 0.38 & \\
& Gender & 0.08 & 0.220 & 0.04 \\
& Units & 0.03 & 0.100 & 0.03 \\
& Years Completed & -0.09 & 0.10 & -0.09 \\
& & & & \\
& Constant 2 & 0.24 & 0.32 & \\
& Gender & -0.13 & 0.180 & 0.07 \\
& Units & 0.00008 & 0.090 & 0.00 \\
& Years Completed & -0.07 & 0.090 & -0.08 \\
& Autonomy & 0.29 & 0.090 & $.32^{* * *}$ \\
& Competence & 0.27 & 0.09 & $.28^{* *}$ \\
& Relatedness & 0.19 & 0.090 & $.20^{*}$ \\
\hline
\end{tabular}

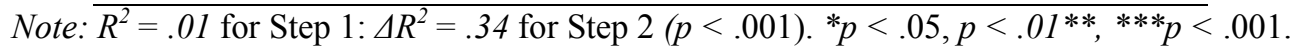

The second step in the mediation analysis was completed by testing if autonomy, competence, and relatedness were significantly related to graduate student program satisfaction. A multiple regression was completed with gender, units, and years in program as covariates; autonomy, competence, and relatedness as the independent variables; and graduate student program satisfaction as the dependent variable. The results of this analysis indicated partial support for Hypothesis 2; autonomy and relatedness were positively related to graduate student program satisfaction when controlling for gender, units, and years in school, $F(6,100)=7.23, p<.001 . \Delta R^{2}=.24$, but competence was not. That is, students who felt that they had higher levels of autonomy and relatedness had higher levels of graduate student program satisfaction. These results can be seen in Table 8 . The $R^{2}$ value indicates almost $25 \%$ of the variability of graduate student program satisfaction is predicted by autonomy and relatedness. 
Table 8. Hierarchical Regression for Doctoral Student Variables on College Satisfaction

\begin{tabular}{llrrr} 
& & \multicolumn{2}{c}{ SE b } & \\
\cline { 3 - 5 } Step 1 & & & & \\
\multirow{2}{*}{ Constant } & -0.18 & 0.35 & \\
& Gender & 0.12 & 0.20 & 0.06 \\
& Units & 0.22 & 0.10 & 0.22 \\
& Years Completed & 0.12 & 0.10 & 0.12 \\
& & & & \\
& Constant & 0.22 & 0.32 & \\
& Gender & -0.12 & 0.18 & -0.05 \\
& Units & 0.21 & 0.09 & 0.21 \\
& Years Completed & 0.11 & 0.09 & 0.11 \\
& Autonomy & 0.31 & 0.09 & $.32^{* * *}$ \\
& Competence & 0.07 & 0.09 & 0.07 \\
& Relatedness & 0.27 & 0.09 & $.27^{* *}$ \\
\hline
\end{tabular}

For the third and fourth steps, a hierarchical regression was completed where the gender, units, and years were inserted in the first step, autonomy and relatedness were inserted in the second step, graduate student program satisfaction was inserted in the final step, and motivation was the dependent variable. These results were also significant, $F(7,84)=7.42, p<.001$, giving partial support to Hypothesis 3 . This indicates that graduate student program satisfaction had unique effects on motivation beyond the effects of autonomy and relatedness. Graduate students who had higher levels of graduate student program satisfaction beyond the impact of autonomy and relatedness had higher levels of motivation than those students with lower levels of graduate student program satisfaction. Moreover, autonomy had a significant relationship with motivation to continue beyond the effects of graduate student program satisfaction as seen in Table 9. This indicates that students who felt they were able to pursue their own research were more motivated to complete graduate school than those who those who had lower autonomy. Autonomy and relatedness are mediated completely by graduate student program satisfaction in their relationship with motivation as indicated by the meeting of the requirements of Baron and Kenny (1986). A Sobel Test (Sobel, 1982) was completed to confirm this result. For autonomy, the Sobel test was significant, Sobel $=1.92, p<.05$, as it was for relatedness, Sobel $=1.87, p<.05$.

Table 9. Hierarchical Regression for Doctoral Student Variables on Motivation

\begin{tabular}{llrrr}
\hline \multirow{3}{*}{ Step 1} & & $b$ & $S E b$ & $\beta$ \\
\cline { 3 - 5 } & & & & \\
& Constant & -0.07 & 0.380 & \\
& Gender & 0.08 & 0.220 & 0.04 \\
& Units & 0.03 & 0.100 & 0.03 \\
& Years Completed & -0.09 & 0.100 & -0.09
\end{tabular}


Step 2

$\begin{array}{llrlc} & \text { Constant } & 0.29 & 0.33 & \\ & \text { Gender } & -0.16 & 0.19 & -0.08 \\ & \text { Units } & -0.03 & 0.09 & 0.03 \\ & \text { Years Completed } & -0.1 & 0.09 & -0.10 \\ & \text { Autonomy } & 0.36 & 0.09 & 0.39^{* * *} \\ & \text { Relatedness } & 0.26 & 0.09 & 0.27^{* *} \\ & & & & \\ & \text { Constant } 3 \text { Gender } & 0.25 & .32 & -0.07 \\ & \text { Units } & -0.15 & 0.19 & -0.02 \\ & \text { Years Completed } & -0.02 & 0.09 & -0.12 \\ & \text { Autonomy } & -0.12 & 0.09 & 0.29^{* *} \\ & \text { Relatedness } & 0.27 & 0.1 & 0.22^{*} \\ & \text { Satisfaction } & 0.2 & 0.09 & .25^{*}\end{array}$

Note. $R^{2}=.01$ for Step $1: \overline{\Delta R^{2}=.33(\mathrm{p}<.001) \text { for Step } 2 ; \Delta R 2=.03(p<.05) \text { for Step } 3 .{ }^{*} p<.05,{ }^{*} * \mathrm{p}}<.01$

\section{Discussion}

\section{Hypothesis 1: Autonomy, Competence, and Relatedness Will Be Positively Related to the Motivation to Continue}

In this study, there was a positive relationship between autonomy, competence, and relatedness and motivation to continue. Doctoral students who felt that they had the freedom to pursue their research interests felt more motivated to continue their program than those who did not feel that they had that freedom. Previous research has indicated that feelings of autonomy are important for doctoral student progress (Girves \& Wemmerus, 1988). Doctoral students who had graduated felt that they had more independence and personal responsibility than those who had not graduated from graduate school (Kluever, 1997). Moreover, when students are treated as junior colleagues, they progress further toward their doctoral degree (Girves \& Wemmerus, 1988). Doctoral students enrolled in high-completing programs were more likely to have felt that they were treated as a junior colleague than those who were in low-completing programs (Ferrer de Valero, 2001).

The results of this study indicated that individuals who felt they had higher levels of competence had higher levels of motivation to continue their program than those who felt they had low levels of competence. Previous research has indicated that research self-efficacy (a construct correlated to competence) has a positive impact on dissertation progress (Faghihi et al, 1999) and productivity (Brown et al, 1996; Hollingsworth \& Fassinger, 2002). In the past, research has not been completed investigating the global perceived competence in doctoral students. However, competence has been reported as being positively related to intrinsic motivation in South Korean high school students (Jang et al, 2009). 
As supported by previous research, the results in this study indicated that students who had high levels of relatedness to their advisor felt more motivated to continue than those who had low levels. Lovitts (2001) indicated that completers of doctoral programs perceived their advisors as more personally interested in them than those students who did not complete their program. Relatedness with advisors also has been indicated to have a positive impact on productivity (Paglis et al, 2006), dissertation progress (Faghihi et al, 1999), time to degree (Potvin \& Tai, 2011; Wao \& Onwuegbuzie, 2011), and high levels of completion within a department (Ferrer de Valero, 2001). Graduate students who had advisors who were supportive, but had high standards, had higher levels of motivation and productivity than those who did not have such advisors (Lan \& Williams, 2005).

\section{Hypothesis 2: Autonomy, Competence, and Relatedness Will Be Positively Related to Graduate School Program Satisfaction}

The second hypothesis was partially supported; autonomy and relatedness were positively related to graduate student program satisfaction, but competence was not. That is, students who felt that they could pursue their own research had more graduate student program satisfaction with their program than those students who did not feel they had that control. Feelings of personal control and the opportunity for independent thought and action have been reported to have a positive relationship with graduate student program satisfaction; satisfaction was defined as how satisfied they were compared to other students with their own performance in graduate school and their relationships with faculty and other students (Madden \& Carli, 1981).

The results in this study also indicated that relatedness to one's advisor and graduate student program satisfaction with one's program were positively related. That is, doctoral students who felt a sense of relatedness with their advisor felt more satisfied with graduate school than those did not have that sense of relatedness with their advisor. Previous research also supports that mentoring and positive advisor relationships are positively related to graduate student program satisfaction (Maton et al, 2011; Nettles \& Millett, 2006, chap. 11; Tenenbaum et al., 2001).

Contrary to the hypothesis, global feelings of competence did not have a significant relationship with graduate student program satisfaction. However, the fact that competence has a strong relationship to motivation to continue graduate school, but not through graduate student program satisfaction, may be the most interesting result in this study. It seems that students who are motivated also feel competent; these students are motivated regardless of their levels of satisfaction.

\section{Hypothesis 3: Mediation Model}

The relationship of autonomy and relatedness to motivation to continue was mediated by graduate student program satisfaction in this study. In fact, graduate student program satisfaction completely mediated the relationship of relatedness and motivation to continue and almost completely mediated the positive relationship between autonomy and motivation to continue. In other words, autonomy predicted graduate student program satisfaction, which predicted motivation to continue. Previous research has indicated that satisfaction is positively related to doctoral program persistence; doctoral students with low levels of graduate student program satisfaction are more likely to consider departing graduate school than those with higher levels of satisfaction (Hesli et al., 2003). These results indicate that graduate student program satisfaction is the critical factor for motivation to continue.

\section{Limitations}

There are several issues related to the sample that limit the generalizability of these results. First, the sample utilized in this study was a convenience sample; the results could be influenced by the 
participants who chose to participate. Second, few of the individuals in the sample were from science disciplines. Further research would need to be done to investigate if these variables are influential for science students. Third, a larger sample and a random sample from the university where this data was collected would make the paper more generalizable. Fourth, while the students who chose to participate in the study were from many disciplines, the data was collected from students who attended one university. To make the results more generalizable, students from many different universities would have to be surveyed.

The use of non-established measures to explore the variables in the study is another issue. The measures for this data set were selected after perceiving the patterns and trends within the data. While the construct measures were demonstrated to be reliable and valid, use of an established instrument would strengthen the results of the study. Autonomy was measured by the freedom to pursue one's own research interests. Competence was measured by feelings of success and capability, and the relatedness variable was focused on a personal relationship between the graduate student and the advisor. Future research should include the development of more items to better capture the latent constructs as well.

\section{Further Research}

This study indicates that having the freedom to pursue one's own research interests is an important factor in graduate student program satisfaction and motivation to continue graduate school. While the research indicates that having the freedom to do one's own research is important, how much freedom is enough should be studied; too much freedom may cause anxiety, and too little may cause boredom (Csikszentmihalyi, 1975). However, this study indicates that feeling like one has research autonomy is important at all levels. While this study included students from a variety of programs, there were not enough participants to investigate how important this factor is in specific programs. It is possible that having this freedom would be more important to students in some programs than others; so this should be investigated. The students who participated in this study ranged from just starting the program to being in the program for six years; further research should investigate how important this type of autonomy is to time-in-program. It seems logical that newer students would need or want less freedom than those who have been in the program longer. Lovitts (2001, chap. 7) reported that satisfied students felt that their advisors gave them enough independence, but also gave them appropriate guidance when it was needed. Longitudinal and cross-sequential studies with large numbers of students at the same stage of their studies would greatly improve the ability to study how the importance of these variables changes over time. Moreover, longitudinal and cross-sequential studies could investigate how the balance between support and autonomy changes through the doctoral programs.

Competence was found to be positively related to motivation to continue, but not graduate student program satisfaction. This indicates that feeling like a competent student makes one motivated to continue the program regardless of levels of satisfaction. Future studies should investigate what specifically makes students feel competent in their doctoral studies. Specifically, students' background variables and doctoral program characteristics should be investigated.

The result that a sense of relatedness to an advisor was positively related to motivation to continue and graduate student program satisfaction was not unexpected; the importance of the advisor has been documented in many other studies (Bair \& Haworth, 1999 Faghihi et al, 1999; Lan \& Williams; 2005; Lovitts, 2001, 2008; Maton et al., 2011; Paglis et al, 2006; Tenenbaum et al., 2011; Zhao et al., 2007). What was not studied in the investigation was a sense of relatedness to peers. Other research has indicated that relationships with other students also are important for doctoral completion (Bair \& Haworth, 1999; Lovitts, 2001, chap. 6). However, there is a difference between relationships and relatedness. Relatedness is feeling valued and cared for (Deci \& 
Ryan, 2000; Deci et al., 1991; Ryan \& Deci, 2000). Future research should investigate what level of relatedness to peers is needed to support doctoral education completion.

While motivation to continue was found to be related to the four other factors, the predictive value of this motivation to continue should be further investigated. For instance, investigations should be done to see if the motivation to continue actually predicts continuation and completion of doctoral programs. This could be done through longitudinal studies. Previous research has indicated that motivation influences high school completion (Vallerand et al., 1997). Vallerand and colleagues (1997) reported that high school students who had self-determined motivation also had high intentions to persist and these intentions were negatively related to high school dropout.

However, further research is needed to discover if motivation at the doctoral level predicts doctoral study completion.

While there are many studies that investigate graduate student program satisfaction, nearly all of them define the construct of doctoral student satisfaction differently. To really understand doctoral student satisfaction, researchers should develop and define what doctoral satisfaction is. Moreover, there appears to be many different types of doctoral satisfaction; how these types of satisfaction interrelate would greatly improve the study of doctoral program satisfaction as a whole.

\section{Implications for Doctoral Faculty}

Based on this research, there are several recommendations to be made. Academic advisors should consider how to balance autonomy and support when assisting students' with their research agendas. So, advisors should give the students autonomy, but be available to the students when the students need help.

As found in previous studies, advisors are critical for doctoral program completion (Bair \& Haworth, 1999; Faghihi et al, 1999; Lan \& Williams; 2005; Lovitts, 2001, 2008; Maton et al., 2011; Paglis et al, 2006; Tenenbaum et al., 2011; Zhao et al., 2007). A spotlight was put on the interpersonal dimensions of the advising relationship in this study. Advisors should select students to work with whom they would be willing to have a friendly relationship. Whether or not the advisor feels a sense of relatedness with their advisees, developing some rudimentary counseling skills (e.g., active listening), and using them with the students, would most likely improve the relationship between the advisor and advisee.

To increase feelings of competence, advisors should keep feedback positive and monitor the students' progress to ensure that they are giving tasks that are both challenging and achievable. Previous research suggests that tasks that are challenging, but achievable, increase feelings of competence (Csikszentmihalyi, 1975; Deci, 1975; Deci \& Ryan, 1985). Moreover, positive feedback increases feelings of competence (Blanck, Reis, \& Jackson, 1984; Deci, 1972). Graduate program directors could check in with students annually to assess the students' feelings of competence; for students who have low levels of competence, interventions could be implemented to increase their feelings of competence.

\section{Conclusion}

The innate psychological needs have been reported as critical components of many aspects of human functioning (Black \& Deci, 2000; Deci et al, 1991; Vansteenkiste et al, 2004). Autonomy, competence and relatedness have been reported as having positive outcomes for the intrinsic motivation, learning, achievement, and persistence of undergraduates and high school students (Black \& Deci, 2000; Vallerand et al, 1997; Vansteenkiste et al, 2004). However, these variables have not been investigated in Ph.D. students. Moreover, this study investigated autonomy in research, overall feelings of competence, and relatedness to advisor in relationship to graduate stu- 
Motivation, Satisfaction, and Innate Psychological Needs

dent program satisfaction and motivation. While feelings of autonomy have been operationalized as choice in coursework, feelings of control, the opportunity for independent thought and action, and being treated as a junior colleague; this study indicates that having the freedom to pursue one's own research interests is a critical component of graduate student program satisfaction and motivation (Field et al., 1974; Girves \& Wemmerus, 1988; Gregg, 1971; Madden and Carli; 1981).

While feelings of competence did not have a relationship with graduate student program satisfaction, it did have a relationship with motivation to continue graduate school. Competence, in graduate students, has only been investigated in graduate students' psychosocial factors (Uqdah et al, 2009). Research on self-efficacy, on the other hand, has been focused on self-efficacy in research, productivity, and dissertation progress (Brown et al., 1996; Hollingsworth \& Fassinger, 2002;

Love et al, 2007; Paglis et al., 2006). In this study, global perceived competence was found to be an important and unique factor for graduate students' motivation to continue their doctoral program.

Similar to competence/self-efficacy, advisor relatedness has been linked to perceived research self-efficacy (Paglis et al, 2006), dissertation progress (Faghihi et al, 1999), satisfaction (Hesli et al, 2003; Lan \& Williams, 2005; Suhre et al, 2007; Zhao et al, 2007), productivity (Lan \& Williams, 2005), and completion of doctoral program (Lovitts, 2001). In this study, advisor relatedness was shown to be related to graduate student program satisfaction and motivation to continue.

\section{References}

Bair, C. R., \& Haworth, J. G. (1999). Doctoral student attrition and persistence: A meta-synthesis. Paper presented at the Annual Meeting of the Association for the Study of Higher Education, San Antonio.

Bandura, A. (1997). Self-efficacy: The exercise of control. New York: W. H. Freeman.

Baron, R. M., \& Kenny, D. A. (1986). The moderator-mediator variable distinction in social psychological research: Conceptual, strategic, and statistical considerations. Journal of Personality and Social Psychology, 51, 1173-1182.

Berelson, B. (1960). Graduate education in the United States. New York: McGraw-Hill Book Company.

Black, A. E. \& Deci, E. L. (2000). The effects of instructors' autonomy support and students' autonomous motivation on learning organic chemistry: Self-determination theory perspective. Science Education, 84, 740-756.

Blanck, P. D., Reis, H. T., \& Jackson, L. (1984). The effects of verbal reinforcement of intrinsic motivation for sex-linked tasks. Sex Roles, 10, 369-386.

Bowen, W. G. \& Rudenstine, N. L. (1992). In pursuit of the Ph.D. Princeton, N.J.: Princeton University Press.

Brown, S. D., Lent, R. W., Ryan, N. E., \& McPartland, E. B. (1996). Self-efficacy as an intervening mechanism between research training environments, and scholarly productivity: A theoretical and methodological extensions. The Counseling Psychologist, 24(3), 535-544.

Carnegie Foundation for the Advancement of Teaching. (n.d.). Graduate Instructional Program Classification. Retrieved from http://classifications.carnegiefoundation.org/descriptions/grad program.php

Csikszentmihalyi, M. (1975). Beyond boredom and anxiety: The experience of play in work and games. Oxford: Jossey-Bass.

Deci, E.L. (1972). Intrinsic motivation, extrinsic motivation, and inequity. Journal of Personality and Social Psychology, 22, 113-120.

Deci, E. L. (1975). Intrinsic motivation. New York: Plenum Press. 
Deci, E. L. \& Ryan, R. M. (1985). Intrinsic motivation and self-determination in human behavior. New York: Plenum Press.

Deci, E. L. \& Ryan, R. M. (1994). Promoting the self-determined education. Scandinavian Journal of Educational Research, 38, 3-14.

Deci, E. L. \& Ryan, R. M. (2000). The "what" and "why" of goal pursuits: Human needs and the selfdetermination of behavior. Psychological Inquiry, 11, 227-268.

Deci, E. L., Vallerand, R. J., Pelletier, L. G., \& Ryan, R. M. (1991). Motivation and education: The selfdetermination perspective. Educational Psychologist, 26, 325-346.

Deci, E. L. \& Vansteenkiste, M. (2004). Self-determination theory and the basic need satisfaction: Understanding human development in positive psychology. Ricercher di Psicologia, 1(27), 23-40.

Faghihi, F., Rakow, E. A. \& Ethington, C. (1999, April). A study of factors related to dissertation progress among doctoral candidates: Focus on students' research self-efficacy as a result of their research training and experiences. Paper presented at the Annual Meeting of the American Educational Research Association, Montreal, Canada.

Feild, H. S., Holley, W. H. \& Armenakis, A. A. (1974). Graduate students' satisfaction with graduate education: Intrinsic and extrinsic factors. The Journal of Experimental Education, 43(2), 8-15.

Ferrer de Valero, Y. (2001). Departmental factors affecting time-to-degree and completion rates of doctoral students at one land-grant research institution. The Journal of Higher Education, 72(3), 341-367.

Furrer, C., \& Skinner, E. (2003). Sense of relatedness as a factor in children's academic engagement and performance. Journal of Educational Psychology, 95, 148-162.

Gardner, S. K. (2008). Student and faculty attributions of attrition in high and low-completing programs in the United States. Higher Education, 58(1), 97-112

Girves, J. E. \& Wemmerus, V. (1988). Developing models of graduate student degree progress. The Journal of Higher Education, 59(2), 163-189.

Gregg, W. E. (1971, February). Graduate student satisfaction: Academic and non-academic. Paper presented at the $55^{\text {th }}$ Annual Meeting of the American Educational Research Association, New York.

Hesli, V. L., Fink, E. C., \& Duffy, D. M. (2003). Mentoring in a positive graduate student experience: Survey results from the Midwest region, Part 1. Political Science and Politics, 36(3), 457-460.

Hollingsworth, M. A. \& Fassinger, R. E. (2002). The role of faculty mentors in the research and training of counseling psychology students. Journal of Counseling Psychology, 49(3), 324-330.

Ivankova, N. V. \& Stick, S. L. (2007). Students' persistence in a distributed doctoral program in educational leadership in higher education: A mixed methods study. Research in Higher Education, 48(1), 93-135.

Jang, H., Reeve, J., Ryan, R. M., \& Kim, A. (2009). Can self-determination theory explain what underlies the productive, satisfying learning experiences of collectivistically oriented Korean students? Journal of Educational Psychology, 101(3), 644-661.

Kehrhahn, M. T., Sheckley, B. G., \& Travers, N. L. (1999, May-June). Effectiveness and efficiency in graduate education. Paper presented at the Annual Forum of the Association for Institutional Research, Seattle, WA.

Kluever, R. C. (1997). Students' attitudes toward the responsibilities and barriers in doctoral study. In L. F. Goodchild, K. E. Green, E. L. Katz, \& R. C. Kluever (Eds.), Rethinking the dissertation process: Tackling personal and institutional obstacles (pp. 47-56). San Francisco: Jossey-Bass.

Lan, W., \& Williams, A. (2005). Doctoral students' perceptions of advising style and development and the relationship between them. NACADA Journal, 25(1), 31-41.

Love, K. M., Bahner, A. D., Jones, L. N., \& Nilsson, J. E. (2007). An investigation of early research experience and research self-efficacy. Professional Psychology Research and Practice, 38(3), 314-330. 
Lovitts, B. E. (1996, April). Who is responsible for graduate student attrition? The individual or the institution. Toward an explanation of the high and persistent rate of attrition. Paper presented at the Annual Meeting of the American Educational Research Association, New York, NY.

Lovitts, B. E. (2001). Leaving the ivory tower: The causes and consequences of departure from graduate study. Lanham, Maryland: Rowman and Littlefield Publishers.

Lovitts, B. E. (2008). The transition to independent research: Who makes it, who doesn't, and why. The Journal of Higher Education, 79(3), 296-325.

Lovitts, B. E., \& Nelson, C. E. (2000). The hidden crisis in graduate education: Attrition from Ph.D. programs. Academe, 86(6). Retrieved from http://www.aaup.org/AAUP/pubsres/academe/2000/ND/Feat/lovi.htm?PF=1

Madden, M. E., \& Carli, L. (1981, April). Students' satisfaction with graduate school and attributions of control and responsibility. Paper presented at the Annual Meeting of the Eastern Psychological Association, New York, NY.

Martens, R., \& Kirschner, P. A. (2004, October). Predicting intrinsic motivation. Paper presented at the meeting of the Association for Education, Community, and Technology, Chicago, IL.

Maton, K. I., Wimms, H. E., Grant, S. K., Wittig, M. A., Rogers, M. R., \& Vasquez, M. J. T. (2011). Experiences and perspectives of African American, Latina/o, Asian American, and European American psychology graduate students: A national study. Cultural Diversity and Ethnic Minority Psychology, $17(1), 68-78$.

Most, D. E. (2008). Patterns of doctoral student degree completion: A longitudinal analysis. Journal of College Student Retention, 10(2), 171-190.

Nerad, M., \& Miller, D. S. (1996). Increasing student retention in graduate and professional programs. In J. G. Haworth (Ed.), Assessing graduate and professional education: Current realities, future prospects (pp. 61-76). San Francisco: Jossey-Bass.

Nettles, M. T., \& Millet, C. M. (2006). Three magic letters: Getting to Ph.D. Baltimore, MD: The John Hopkins University Press.

Paglis, L. L., Green, S. G., \& Bauer, T. N. (2006). Does advisor mentoring add value? A longitudinal study of mentoring and doctoral student outcomes. Research in Higher Education, 47(4), 451-478.

Potvin, G., \& Tai, R. H. (2011). Examining the relationships among doctoral completion time, gender, and future salary prospects for physical scientists, Journal of Chemical Education, 89, 21-28.

Ryan, R. M., \& Deci, E. L. (2000). Self-Determination Theory and the facilitation of intrinsic motivation, social development, and well-being. American Psychologist, 55(1), 66-78.

Sobel, M. E. (1982). Asymptotic confidence intervals for indirect effects in structural equation models. Sociological Methodology, 13, 290-312.

Suhre, C. J. M., Jansen, E. P. W. A., \& Harskamp, E. G. (2007). Impact of degree program satisfaction on the persistence of college students. Higher Education, 54, 207-226.

Tenebaum, H. R., Crosby, F. J., \& Gliner, M. D. (2001). Mentoring relationships in graduate school. Journal of Vocational Behavior, 59, 326-341.

Tucker, A. (1964). Factors related to attrition in doctoral students (Cooperative Research Project No. 1146). Washington, D.C.: United States Office of Education.

Uqdah, A. L., Tyler, K. M., \& DeLoach, C. (2009). Academic attitudes and psychological well-being of Black American psychology graduate students. The Negro Education Review, 60, 23-38.

Vallerand, R. J., Fortier, M. S., \& Guay, F. (1997). Self-determination and persistence in a real-life setting: Toward a motivational model of high school dropout. Journal of Personality and Social Psychology, 72(5), 1161-1176. 
Vansteenkiste, M., Simons, J., Lens, W., Sheldon, K. M., \& Deci, E. L. (2004). Motivating learning, performance, and persistence: The synergistic effects of intrinsic goal contents and autonomy-supportive contexts. Journal of Personality and Social Psychology, 87, 246-260.

Wao, H. O., \& Onsuegbuzie, A. J. (2011). A mixed research investigation of factors related to time to the doctorate in education. International Journal of Doctoral Studies, 6, 115-134. Retrieved from http://ijds.org/Volume6/IJDSv6p115-134Wao320.pdf

Wasbrun-Moses, L. (2008). Satisfaction among current doctoral students in special education. Remedial and Special Education, 29(5), 259-268.

Wentzel, K. R. (1998). Social relationships and motivation in middle school: The role of parents, teachers, and peers. Journal of Educational Psychology, 90, 202-209.

Willis, B., \& Carmichael, K. D. (2011). The lived experience of late-stage doctoral student attrition in counselor education. The Qualitative Report, 16(1), 192-207.

Zhao, C. M., Golde, C. M., \& McCormick, A. C. (2007). More than a signature: How advisor choice and advisor behavior affect doctoral student satisfaction. Journal of Further and Higher Education, 31, 263-281.

\section{Biography}

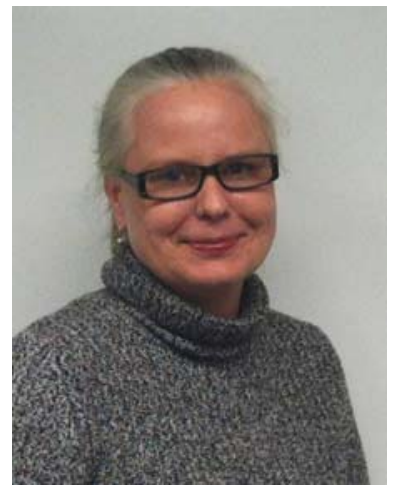

Michelle M. Mason, Ph.D. is an Assistant Professor of Psychology at Troy University in Montgomery, Alabama. She graduated in 2009 from Claremont Graduate University with a degree in developmental psychology. She is currently doing research in the areas of love of learning and doctoral student motivation. 